\title{
Robot-assisted lobectomy
}

\author{
Robert C. Ashton, Jr, MD, Cliff P. Connery, MD, Daniel G. Swistel, MD, and Joseph J. DeRose, Jr, MD, New York, NY
}

$\mathrm{V}$ ideo-assisted thoracoscopic surgery (VATS) for anatomic pulmonary resections continues to develop since its application in the early 1990 s. $^{1-5}$ Using the da Vinci Surgical System (Intuitive Surgical, Inc., Mountain View, Calif), we performed an anatomic right lower lobectomy for stage Ia non-small cell lung cancer.

\section{Clinical and Technical Description}

A 48-year-old woman was found to have a 1-cm nodule that had increased in size compared with its size at previous computed tomographic scans. After negative bronchoscopic and mediastinoscopic results, a VATS wedge resection confirmed non-small cell lung cancer. A formal lobectomy was then performed.

Incisions for the VATS included a posterior 1-cm incision in the fifth intercostal space, an anterior $1-\mathrm{cm}$ incision in the fifth intercostal space, and a $1-\mathrm{cm}$ incision in the eighth intercostal space. For the lobectomy, the anterior incision was extended to a 6-cm working incision. A 1-cm incision was made anteriorly in the seventh intercostal space, and a 7-mm incision was made in the fourth intercostal space. The entire procedure was performed with the zero-degree scope. The robotic arms were placed in the fourth and eighth intercostal space incisions, the camera was placed in the working incision, and the robotic cart was positioned posteriorly over the right shoulder (Figure 1). The inferior pulmonary ligament was mobilized to the level of the inferior pulmonary vein. Next the hilum was dissected anteriorly, identifying the pulmonary veins. The inferior pulmonary vein was dissected, and a $0-0$ silk tie was placed around it. An endovascular stapler was then used to divide the vein. The fissure was dissected, identifying the pulmonary artery to the lower lobe. After complete dissection of the pulmonary artery, the branches to the lower lobe and middle lobe were identified. Lymph nodes on the pulmonary artery were dissected as separate samples. The pulmonary artery was encircled with a 0-0 silk tie, and an endovascular stapler was used to divide the pulmonary artery. Next the bronchus to the lower lobe was dissected and encircled with an umbilical tape. A TA stapler (United States Surgical Corporation, Norwalk, Conn) was used to divide the bronchus. Before cutting the bronchus, the lung was

From the Department of Surgery, St Luke's Roosevelt Hospital Center, College of Physicians and Surgeons, Columbia University, New York, NY.

Received for publication Sept 13, 2002; accepted for publication Nov 25, 2002 .

Address for reprints: Robert C. Ashton, Jr, MD, FACS, FCCP, St Luke's Roosevelt Hospital Center, College of Physicians and Surgeons, Columbia University, Suite 2B07, 1000 Tenth Ave, New York, NY 10019 (E-mail: rashton@chpnet.org).

J Thorac Cardiovasc Surg 2003;126:292-3

Copyright $(C) 2003$ by The American Association for Thoracic Surgery

$0022-5223 / 2003 \$ 30.00+0$

doi:10.1016/S0022-5223(03)00201-0

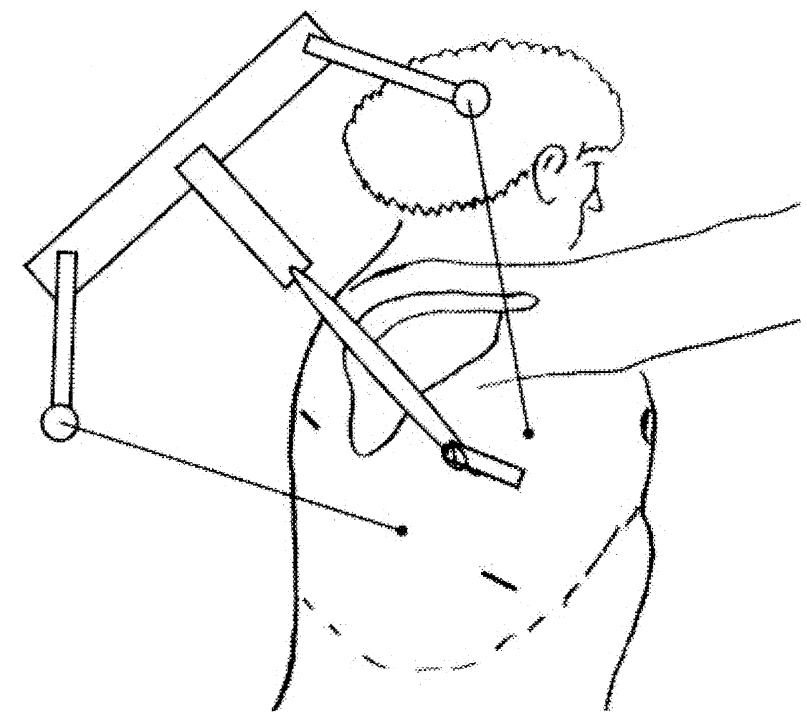

Figure 1. Incisions noted are a posterior 1-cm incision in the fifth intercostal space and an anterior 1-cm incision in the seventh intercostal space. The scope is placed in the working incision in the fifth intercostal space. The robotic arms are placed in the fourth and eighth intercostal spaces. The robotic cart is positioned posteriorly over the right shoulder.

inflated to ensure ventilation of the middle and upper lobes. A branch of the pulmonary artery to the superior segment of the lower lobe was identified and divided with an endovascular stapler. The fissure was completed with an endostapler. The lower lobe was removed in an Endobag tissue retrieval system (Medisco Medical Systems, Swindon, United Kingdom). The bronchus was examined for any evidence of an air leak, and the vessels were examined for any bleeding. The patient had a mediastinoscopy, the results of which were negative, and therefore no further lymph node dissection was performed.

\section{Results}

The approximate operative times were as follows: bronchoscopy, mediastinoscopy, and pathology, 90 minutes; repositioning and draping, 40 minutes; thoracoscopic wedge resection and pathology, 70 minutes; lobectomy, 330 minutes; total time, 530 minutes. Blood loss was $200 \mathrm{~mL}$, and total fluid replacement was $3 \mathrm{~L}$ of crystalloid solution. Length of stay was 4 days. The patient did not have any complications. Pain control consisted of a paravertebral block for 24 hours. Patient-controlled analgesia with morphine was used, $30 \mathrm{mg}$ for the first 24 hours and $89 \mathrm{mg}$ for the second 24 hours. Subsequently, oral acetaminophen (INN: paracetamol)oxycodone was prescribed. The patient reported not using any pain medication after discharge. 


\section{Technical Considerations}

The port placement and dissection is similar to that of a VATS lobectomy. The working incision should be placed over the major fissure on the basis of examination with either the thoracoscope or robotic scope. During the robotic portion of the procedure, the scope is placed in the working port. Modifications of port placement will be necessary depending on the patient's body habitus, the patient's lung anatomy, and the location of the tumor. A working port is recommended for control of the hilum and major vessels and is necessary to remove the specimen at the conclusion of the procedure.

\section{Comment}

The da Vinci Surgical System has several advantages over thoracoscopic surgery. The enhanced optics, which include 3-dimensional visualization and $12 \times$ magnification provide superior visualization than what is currently available in thoracoscopy. The surgical arms have distal endowrists, which simulate normal wrist movement, have scaled motion, and remove hand tremors. With the maneuverability of the endowrists and enhanced visualization, precise dissection of tissue and control of vessels is obtainable.
Robot-assisted lobectomy is a procedure that will continue to evolve. An understanding of robotic technology and VATS lobectomy are required to perform this procedure. This procedure requires a dedicated team approach, with a console and tableside surgeon. This case demonstrates the feasibility of performing an anatomic pulmonary resection with the da Vinci Surgical System.

\section{References}

1. Roviaro G, Rebuffat C, Varoli F, Vergani C, Mariani C, Mariocco M. Videoendoscopic pulmonary lobectomy for cancer. Surg Laparosc Endosc Percutan Tech. 1992;2:244-7.

2. Kirby TJ, Mack MJ, Landreneau RJ, Rice TW. Initial experience with video-assisted thoracoscopic lobectomy. Ann Thorac Surg. 1993;56: 1248-53.

3. McKenna RJ. Lobectomy by video-assisted thoracic surgery with mediastinal node sampling for lung cancer. J Thorac Cardiovasc Surg. 1994;107:879-82.

4. McKenna RJ, Wolf RK, Brenner M, Fischel RJ, Wurnig P. Is lobectomy by video-assisted thoracic surgery an adequate cancer operation? Ann Thorac Surg. 1998;66:1903-8.

5. Yim PC. VATS major pulmonary resection revisited-controversies, techniques, and results. Ann Thorac Surg. 2002;74:615-23.

\title{
Transcardiac gunshot wound recognized forty-eight years later
}

\author{
James B. McClurken, MD, ${ }^{a}$ William J. Hammer, MD, ${ }^{b}$ and Bradford J. Lin, MD, ${ }^{b}$ \\ Abington and Philadelphia, $\mathrm{Pa}$
}

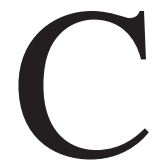

urrent treatment for transcardiac gunshot wounds (GSWs) includes expedient surgical repair. We performed coronary revascularization on a veteran of the Korean conflict who had been shot in the left axilla. The bullet was retrieved 2 days after the GSW through a superficial right chest wall incision, and the patient was told the missile "missed his heart by an inch." During the recent revascularization, plug-like calcific scars proved entrance at the lateral left atrium base of the appendage and exit at the right atrium midlateral wall. Thus this might represent the first reported survivor of a transcardiac GSW without direct repair.

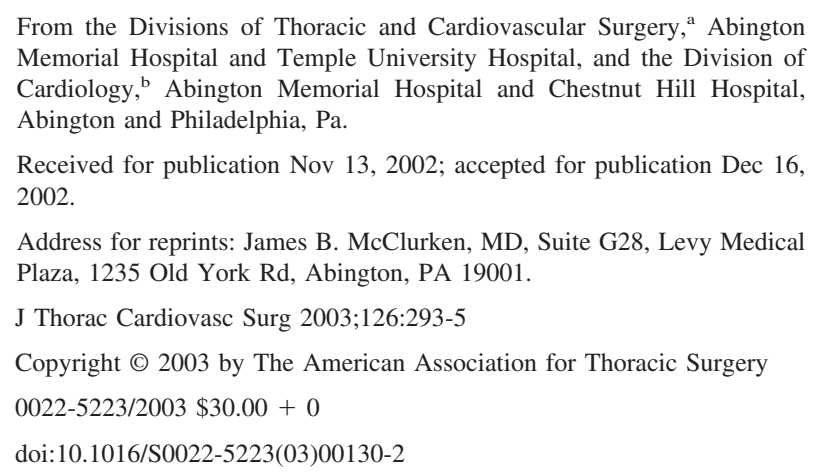

\section{Clinical Summary}

A 70-year-old hypertensive man had worsening stress test results. Catheterization revealed a $35 \%$ lesion of the left main coronary artery, a $90 \%$ blockage of the ostium of the left anterior descending artery (LAD), and a $60 \%$ mid-LAD blockage involving a large diagonal branch with multiple $30 \%$ to $40 \%$ lesions involving all other vessels. Echocardiography revealed left ventricular hypertrophy, mild mitral regurgitation, mild tricuspid regurgitation, and normal left ventricular function. Neither an atrial nor a ventricular septal defect was seen.

The history was significant for a GSW to the chest. The patient stated he was wearing a flak jacket while on patrol in June 1953, when he was hit 7 times by bullets to the torso. The flak jacket deflected 6 of the bullets, but a seventh entered the left axilla (Figure 1, A). Because of the hostile fire, a medic dressed the wound and informed the patient he would have to walk 3 miles to the nearest mobile army surgical hospital. On arrival, the patient collapsed into the tent. Resuscitation included 3 pints of blood; he described subcutaneous emphysema of the entire chest wall.

The patient was then transferred to Tokyo, where a US military surgical team performed a lateral thoracic incision (Figure 1, B) and removed the bullet from superficial tissue, stating the flak 